DOI: $10.1515 / \mathrm{rpp}-2016-0020$

Master of Technology Degree, Assistant Professor, SHRISH BAJPAI Integral University, India Address: Kursi Rd., Lucknow, Uttar Pradesh, India E-mail: shrishbajpai@gmail.com

Undergraduate Student, SIDDIQUI SAJIDA ASIF Integral University, India

Address: Kursi Rd., Lucknow, Uttar Pradesh, India E-mail: sajida2907@gmail.com Undergraduate Student, SYED ADNAN AKHTAR

Shiv Nadar University, India Address: 91 National Hwy., Greater Noida, Uttar Pradesh, India E-mail: adnan.wasazra@gmail.com

\title{
ELECTROMAGNETIC EDUCATION IN INDIA
}

\section{ABSTRACT}

Out of the four fundamental interactions in nature, electromagnetics is one of them along with gravitation, strong interaction and weak interaction. The field of electromagnetics has made much of the modern age possible. Electromagnets are common in day-to-day appliances and are becoming more conventional as the need for technology increases. Electromagnetism has played a vital role in the progress of human kind ever since it has been understood. Electromagnets are found everywhere. One can find them in speakers, doorbells, home security systems, anti-shoplifting systems, hard drives, mobiles, microphones, Maglev trains, motors and many other everyday appliances and products. Before diving into the education system, it is necessary to reiterate its importance in various technologies that have evolved over time. Almost every domain of social life has electromagnetic playing its role. Be it the mobile vibrators you depend upon, a water pump, windshield wipers during rain and the power windows of your car or even the RFID tags that may ease your job during shopping. A flavor of electromagnetics is essential during primary level of schooling for the student to understand its future prospects and open his/her mind to a broad ocean of ideas. Due to such advancements this field can offer, study on such a field is highly beneficial for a developing country like India. The paper presents the scenario of electromagnetic education in India, its importance and numerous schemes taken by the government of India to uplift and acquaint the people about the importance of EM and its applications.

Key words: electromagnetism, electromagnetic education, Indian government initiatives for EM Education, electromagnetic engineering.

\section{INTRODUCTION}

The chronology of electromagnetism goes back from over two thousand years ago. The ancient history of electromagnetism shows that Pliny, in $1^{\text {st }}$ century $\mathrm{BC}$, recorded the story of a shepherd Magnes, (who discovered that iron stones have some magnetic properties) that he was once taking his herds to pasture and he found out that the nails of the shoes he was wearing and the iron ferrel of his staff adhered to the ground and hence made this discovery. The Ancient Greeks considered that light objects like hair could be attracted by the amber buttons and that a spark would jump if the amber was rubbed 
sufficiently (Byrne, 2011). Modern history of electromagnetism shows that in 1550 electrical and magnetic forces were distinguished by G. Cardano in De subtilitate rerum and in 1646 Sir T. Browne in Pseudodoxia Epidemica first coined the word electricity. In 1865 the landmark paper of J. Maxwell was published - "A Dynamical Theory of the Electromagnetic Field", in which his equations illustrated that electric and magnetic forces are two complementing aspects of electromagnetism (Sadiku, 2001). In 1911 H. K. Onnes discovered superconductivity. Anywhere in the world there is no such industry which would not use electromagnetic (EM) engineering. Wireless communication has been introduced in the First World War as a radio communication for the limited area. After that there are major developments in wireless and wire communication field as well as in associated devices. Now, EM associated devices are used in daily life be it kitchen appliances or in office automation, use of EM is tremendous (Kshetrimayum, 2012).

\section{THE AIM OF THE STUDY}

In this paper we aim to study what is electromagnetics and why its education is important for the development of a country and what steps are taken by the government to promote electromagnetics in India. Government initiatives are always very instrumental in defining how the country progresses in various spheres of life. Education is a quintessence of technical progress of a country (Bajpai, Khare, 2015). The resources such as qualified teachers, lab equipment, as meager they happen to be, are very acute problems in India. To handle the current scenario and to deliver to the needs of educating the growing population, it is very necessary that we also resort to digital learning beyond the regular classrooms as and when required. The government of India has come up with many such successful implementations, which can be exploited to study electromagnetics. Beyond this, there are also virtual labs as there are virtual classrooms, which enable to imbibe the very essence of this widely used subject of study as the following sections illuminate (Banerjee, Muley, 2007).

\section{THEORETICAL FRAMEWORK AND RESEARCH METHODS}

Theoretical framework of our research includes the present condition of the education system of EM engineering in India focussing on electromagnetics, steps taken by the government on this discipline of education and future plan of this stream of education. Mainly, the exact statistics which we have used in this paper are provided by the various websites of the government of India. These websites along with some of our observations have led to the complete information we have put in this paper. As we ourselves have gone through the education system in India, we can suggest now what changes should be made in the curriculum or how the students can now increase their knowledge. We have observed that EM is a promising field and hence bowing its seed since earlier classes can prove beneficial for the progress of the education system in India. So, various websites have been set up and government is also taking initiatives to promote it in India. This paper intends to cover all these topics and provides information about how anyone can learn about EM in whichever way it is suitable for them. We have collected various information related to it which are described in the following sections.

From the methodological view, the research was based on interdisciplinary and semantic approaches.

\section{RESULTS}

Statistically, India is the second largest county by population with the biggest population of youth in the world. But, what counts the most is that it has one of the largest numbers of school and college students in the world. An Indian education system is divided into two major sections which are school and college levels. School level is further divided into two parts - primary and secondary education level. College level education is divided 
into two parts - undergraduate and postgraduate education level (Khare, Bajpai, Bharati, 2015).

In class $10^{\text {th }}$ itself the seed of EM education is sown at a primary level which includes basic introduction about electricity, magnetic effects of electric current, right hand thumb rule and which includes around $15 \%$ to $20 \%$ course of the subject science. In class $12^{\text {th }}$ the students are taught about the electric charges and fields, electrostatic potential and capacitance, moving charge and magnetism, electromagnetic induction, electromagnetic spectrum, electromagnetic waves and some basic electromagnetic laws in the subject physics, which is common to the students who opt biology or mathematics in their $10+2$ examination. Some experiments of the EM wave have been included in the physics lab experiments, which are a part of $10+2$ board examination. Electromagnetism also covers up as a major part in each engineering and medical entrance examination in physics section (Goyal, Aggarwal, 2015).

The course of B.Sc. Physics includes major subjects like electromagnetic theory, computational physics, optics, microwave communication which covers major topics like Maxwell's Equations, Reflection and Refraction of Electromagnetic waves and Polarization of Electromagnetic waves. The course of M.Sc. Physics includes major subjects like electrodynamics (Cheney, Ruzzi, Muralidharan, 2005; Agarwal, 2009). At technical education level, in undergraduate level education (BE or B.Tech), physics, which is offered in the first year curriculum of every engineering trade are topics associated to the electrostatics and magnetostatics. Electromagnetic education is offered as a core and optional subject in different specialization of electronics and electrical engineering and few optional subjects are offered in mechanical and aeronautics engineering trades. The core subjects which are electromagnetic field theory, antenna and wave propagation, microwave communication, wireless communication, optical communication with optional subjects related to the topics such as computational electromagnetic, wireless networks, microwave devices which are open to the students of electronics, electrical, mechanical and aeronautics engineering. Postgraduate engineering ( $\mathrm{ME}$ or $\mathrm{M}$. Tech) education of EM education is offered under the specialization Digital Communication, Communication System, Optics or Photonics, RF and Microwave etc. Students studying under these specialization work for their final semester dissertation. Research degree (Doctoral and Post-Doctoral) work under the EM education in India is more focused on antenna problems, microwave devices, communication systems, optics, cellular networks etc. EM related subjects cover around $15 \%$ marks weightage in GATE examination of electronics engineering. There are plenty of books available on the subjects related to the EM. Many Indian authors wrote the material associated to the EM theory. P. K. Chatruvedi, A. Das, S. Das, R. S. Kshetrimayum, V. Mishra, A. Pramanik, K. D. Prasad, G. S. Raju are Indian authors who wrote the textbooks related to the core courses of electromagnetism. MATLAB, NI-LabVIEW, Mathematica are the major simulation tools used for solving mathematical computation problems (Iskander, 1993; Iskander, 2002). Open source tools like Scilab, Maxima, GNU Octave, Freemat and R are also useful for solving mathematical computation problems. Indian government took the initiative to develop the video lecture of the famous professors from premium institutions under the program known as NPTEL which is freely accessible and downloadable from the web. In NPTEL many professors have added their videos related to the topics of EM education, some of them being D. K Ghosh from IIT Bombay, Dr. Sh. Aditya and many more have given the video lecture on the different courses related to EM (Khare, Chowdhry, Bajpai 2014; Kingdon, 2007). 
Indian Government Efforts

Online Video Lecture Repository Development: NPTEL

NPTEL abbreviated as National Programme on Technology Enhanced Learning is a joint initiative of the IITs and IISc. Through this initiative, online courses are offered as well as certification exam is taken at a nominal fee. It offers self-study courses across engineering, humanities and sciences. Recently, various study centres have also been set-up in collaboration with various institutions in India to encourage more students to participate. For this, suitable mentors are identified for various courses and they ensure that the students are judicially devoting themselves to the course including submission of assignments and they may ask doubts as well. NPTEL is the most viewed educational channel on YouTube. $875+$ courses are available online with around 18500 videos across engineering, sciences and humanities. $30+$ online certification courses are available. It has $210+$ million page views (Krishnan, 2009).

NPTEL has numerous online courses available related to Electromagnetics by distinguished and highly qualified teachers like Dr. R. Bhattacharjee from IIT Guwahati on Electromagnetic Fields, Prof. M. K. Gunasekaran from IISc Bangalore on Electromagnetic Compatibility for Circuit Designers and many other professors have uploaded their lectures and notes along with the syllabus for the ease of the students to understand each topic clearly. Also, doubts can be asked which are answered by the professors themselves hence creating a very useful and fruitful platform for the students to understand the concepts thoroughly (Ananth, 2011).

SAKSHAT: It is an initiative of NMEICT (National Mission for Education in ICT). It aims to address all the education and learning-related needs of the student, teachers and lifelong learners. FOSSEE (Free and open Source Software for Education) is another programme under SAKSHAT which aims to improve the quality of learning, allow freedom in education, create a constructive and innovative learning and teaching environment, enable and motivate students, faculty and other users to use open source software.

Various programmes exist which greatly ease learning for students. There are options to remotely connect to a teacher through A-view, a web conferencing tool developed under the mission.

\section{Virtual Labs}

Virtual labs are a phenomenon in today's world. It is an initiative of Ministry of Human Resource Development (MHRD) under the National Mission on Education through ICT. With trained faculty and expensive equipment being a scarce resource in today's institutions, the virtual labs concept comes to the rescue and solves problems effectively. $\mathrm{Be}$ it an undergraduate, postgraduate or a research level scholar, virtual labs are available to all of them. It aims to motivate students to conduct experiments by triggering their curiosity. It enables the students to avail various tools for learning such as additional webresources, video lectures, animated demonstrations and self-evaluation. There is always a disinclination to provide sophisticated instruments to students. The rising computer and Internet usage facilitates students and researchers to feel the reality of an experiment and make the theory credible to them. Also, in a developing country like India, instruments and equipment, which are expensive, need to be shared with fellow researchers to the extent possible. So, through remote experimentation, this would help in learning basic and advanced concepts. Today, most of the equipment has a computer interface for data storage and control. The learning of a student could be enhanced as it is possible to design good experiments around some of these equipments (Azad, Auer, Judson, 2011). 
In various models the programme can be implemented. For example, by using set of equations, a phenomenon maybe modelled and by carrying out simulations, the results may be obtained of the particular experiment to approximate the real world result. Alternately, actual data previously obtained can be used to for virtual experiment. Still another way maybe that the experiment is triggered remotely in an actual lab and the observation may be obtained through a computer interface. For those parts of experiment where there is a requirement of "touch and feel", the students can actually visit the laboratory for a short duration.

Virtual lab for electromagnetics is available at Amrita Vishwa Vidyapeetham University. The experiments include: Tangent galvanometer, Van de Graff generator, Magnetic field along the axis of a circular carrying current, Quincke's method, Deflection magnetometer, Barkausen effect, Temperature coefficient of resistance, Andersons Bridge etc (Afsarmanesh, Kaletas, Benabdelkader, Garita, Hertzberger, 2001).

Shodhaganga: Thesis Collection Database

Shodhaganga is a reservoir of Indian Thesis. It stands for the reservoir of Indian intellectual output hosted and maintained by the INFLIBNET Centre and stored in a repository. DSpace is an open source repository software set up the Shodhganga@INFLIBNET developed in partnership between Hewlett-Packard (HP) by MIT (Massachusetts Institute of Technology). Internationally recognized protocols and interoperability standards are used by DSpace. For research scholars, Shodhganga is a platform to submit their $\mathrm{PhD}$ theses and make it available to the entire scholarly community in open access.

Shodhganga replicates academic structure of each University in terms of Centres/ College/Departments. So this structure helps the research scholars from universities to deposit their theses in the respective Centre/College/Department (Bajpai, Khare, Yadav, 2016).

Development of online Textbook Companion Project (TBC)

Scilab is an open source and free software for numerical computation which includes hundreds of mathematical functions and programing language through which we can access advanced data structures, graphical functions like 2-D and 3-D and for scientific and engineering applications. It proves to be a powerful computing environment. Interested users simply need to create an account and download the resources available to learn Scilab from the various resources available (Bajpai, Khare, Yadav, 2016).

\section{Future prospects}

Indian government has taken several steps for the growth industry related to (electromagnetics) EM engineers. Make in India initiative by the honorable Prime Minister of India Mr. N. Modi is a step to put the manufacturing units in India which are not present till now across India such as cell phone manufacturing, electronics devices etc. Due to this, demand for trained EM engineers will arise. Indian government has taken certain steps, which were mentioned in the above sections to encourage the EM education with the help of renowned faculty and researchers in the premium technical institutions. Moreover, Virtual labs solve the problems of the labs which is of a major constrain. Make in India initiative brought up by Honourable Prime Minister Narendra Modi has brought up several opportunities related to electromagnetic field job opportunities as many semiconductors associated companies are setting up their base in India (Indian Government, 2015).

The present scenario of jobs is such that almost all jobs other than a goat herder use some type of electromagnet. Many smartphone makers, electronics and automobile companies have announced their manufacturing units in India. ISRO and DRDO organizations, which operate under Government of India, usually have a very methodical way of selecting their employees. Both the organizations conduct nationwide exams each 
year and the selected candidates have to go through interviews as well. The roles at entry level are very much operational in nature, i.e. one usually spends much amount of time in the laboratories conducting experiments or creating Proof of Concepts which are already available in theory. It is usually a pure Research and Development role. Coherent Directed Research Areas in DRDO includes research areas of interest like: Synthesis and characterization of New Material such as Ferroelectrics, Ferromagnetic, Optimization of materials and technologies such as numerical modelling with the use of frequency selective surfaces and simulations and active Camouflage/Cloaking Devices and some of the research areas in ISRO includes Space technology like design of propulsion systems and optimization; aerodynamics and heat transfer problems related to space vehicles; control systems and guidance for launch vehicles and spacecraft; polymer chemistry, ultra-lightweight structure; propellant technology, satellite energy systems; space electronics, orbital mechanics, space communication systems; computer sciences and new material development. So, the people interested in these topics and whose basics are strong can easily land a job in such esteemed organizations. With the rise of wireless communication, the basic knowledge of electromagnetism is obligatory and as the technology has now advanced i.e. $3 \mathrm{G}$ technologies are mostly in use and 4G technology is being rolled out; more and more EM related candidates will be required in the upcoming time to progress, as a nation in terms of technology and science.

\section{CONCLUSIONS}

Initiatives taken by the government to encourage EM education in India itself proves how much this field is important and the various benefits it has to offer. To obliterate the lack of knowledge related to EM, the tools, which are made available by the government, help thoroughly and doubts related to any topic can be cleared by the experts. This paper hence concludes the various schemes set up by the government and their benefits for the bright future of the country in terms of knowledge and development. Electromagnetism can be said to be the most inevitable field of science or engineering for the proper development of industries in any developing or developed nation. EM is a field which has developed rapidly in the $19^{\text {th }}$ century. It is the base for telecommunication, airline, broadcast industry, etc. which developed rapidly in the last decade in India. Indian government should focus to set up specialist research centres for EM across India. Indian Government should also increase the funding in research activities which will give motivation to more people to do research, leading to increase in development and new ideas which may help to shape up the future of India.

\section{REFERENCES}

1. Afsarmanesh, H., Kaletas, E. C., Benabdelkader, A., Garita, C., Hertzberger, L. O. (2001). A Reference Architecture for Scientific Virtual Laboratories. Future Generation Computer Systems, No 17 (8), pp. 999-1008.

2. Agarwal, P. (2009). Indian Higher Education: Envisioning the future. New Delhi, California, London, Singapore : SAGE Publications Pvt. Ltd, 520 p.

3. Ananth, M. S. (2011). National Programme on Technology Enhanced Learning (NPTEL): The Vision and the Mission. In: Proceedings of IEEE International Conference on Technology for Education (T4E) (14-16 July 2011). Chennai, Tamil Nadu : IEEE, 8 p.

4. Azad, A., Auer, M., Judson, V. (2012). Internet Accessible Remote Laboratories: Scalable E-Learning Tools for Engineering and Science Disciplines: Scalable E-Learning Tools for Engineering and Science Disciplines. Hershey PA : IGI Global, 645 p. 
5. Bajpai, S., Khare, S. (2015). Mechatronics Engineering Education in India. Comparative Professional Pedagogy, Volume 5, Issue 4, pp. 73-79.

6. Bajpai, S., Khare, S., Yadav, R. (2016). Control Education in India: Present \& Future. IFAC-PapersOnLine, Volume 49, Issue 1, pp. 813-818.

7. Banerjee, R., Muley, V. P. (2007). Engineering Education in India. Report to Energy Systems Engineering, IIT Bombay. Powai, Mumbai : Observer Research Foundation, 147 p.

8. Byrne, Ch. (2015). A Brief History of Electromagnetism. Lowell : University of Massachusetts, $20 \mathrm{p}$.

9. Cheney, G. R., Ruzzi, B. B., Muralidharan, K. (2005). A Profile of the Indian Education System. Washington, DC : National Center on Education and the Economy, 29 p.

10. Goyal, Sh., Aggarwal, P. (2015). Indian Education System: from Ancient Period to Present Era. Shikshan Anveshika, Volume 5, Issue 2, pp. 61-67.

11. Indian Government. (2015). Make in India. Retrieved 08.09.2015 from : http://www.makeinindia.com/.

12. Iskander, M. F. (1993). Computer-based Electromagnetic Education. IEEE Transactions on Microwave Theory and Techniques, Volume 41, Issue 6, pp. 920-931.

13. Iskander, M. F. (2002). Technology-based Electromagnetic Education. IEEE Transactions on Microwave Theory and Techniques, Volume 50, Issue 3, pp. 1015-1020.

14. Khare, S., Bajpai, S., Bharati, P. K. (2015). Production Engineering Education in India. Management and Production Engineering Review, No 6 (1), pp. 21-25.

15. Khare, S., Chowdhry, S., Bajpai, S. (2014). Control Engineering Education in India. In: Proceedings of International Conference on Power, Control and Embedded Systems (ICPCES) (26-28 December 2014). Allahabad : IEEE, 4 p.

16. Kingdon, G. G. (2007). The Progress of School Education in India. Oxford Review of Economic Policy, No 23 (2), pp. 168-195.

17. Krishnan, M. S. (2009). NPTEL: a Programme for Free Online and Open Engineering and Science Education. In: Proceedings of International Workshop on Technology for Education (4-6 August 2009). Bangalore : IEEE, 5 p.

18. Kshetrimayum, R. S. (2012). Electromagnetic Field Theory. New Delhi : Cengage Learning, $402 \mathrm{p}$.

19. Sadiku, M. (2001). Elements of Electromagnetics. New York : Oxford university press, $896 \mathrm{p}$. 